\title{
Reference Values of Fetal Peak Systolic Velocity in the Middle Cerebral Artery at 19-40 Weeks of Gestation in Nepalese Population
}

\author{
Shrestha U, ${ }^{1}$ Shrestha I, ${ }^{2}$ Ghimire RK, ${ }^{1}$ Paudel $\mathbf{S}^{1}$ \\ ${ }^{1}$ Department of Radiodiagnosis and Imaging, Kathmandu, Nepal \\ ${ }^{2}$ Department of Obstetrics and Gynaecology, Kathmandu, Nepal.
}

\begin{abstract}
Aims: The purpose of this study was to construct new reference range for fetal middle cerebral artery peak systolic velocity (MCA-PSV) in uncomplicated pregnancy at 19-40 weeks of gestation.
\end{abstract}

Methods: This was a prospective cross-sectional study involving 400 singleton pregnancies between 19 and 40 weeks of gestation without any known risk factors of adverse pregnancy outcome who were referred for routine obstetric examination. The protocol included the doppler examination of fetal middle cerebral artery (MCA) within $2 \mathrm{~mm}$ after its origin from the internal carotid artery and data were used to construct the normograms and percentile fitted curves of each doppler parameter for different gestational age.

Results: Among 400 singleton uncomplicated pregnancies between 19 and 40 weeks of gestation maximum number of pregnancies $(10 \%)$ was at 19 weeks of gestation and minimum $(2.5 \%)$ was at 31 weeks. The fetal peak systolic blood flow in the MCA showed significant correlation with period of gestation. Mean MCA-PSV was $22.35 \pm 3.05$ at 19 weeks of gestation which increased to $67.73 \pm 9.92$ at 40 weeks. The MCA-PSV showed continuous increment with increasing gestational age

Conclusions: Continuous increment in the peak systolic volume with advancing gestational age was obtained which was consistent with the previous studies done by various authors. The percentile fitted values and normograms will be valuable for the serial measurement of the peak systolic volume of the middle cerebral artery for complicated pregnancies.

Keywords: fetal middle cerebral artery, fetal peak systolic velocity, pregnancy.

\section{INTRODUCTION}

Introduction of doppler velocimetry to obstetrics offered a non-invasive method of assessing fetoplacental circulation. ${ }^{1}$ Advance of ultrasonogaphy have revolutionized prenatal diagnosis of fetal anemia and intrauterine-growth-restriction (IUGR). ${ }^{2}$ Use of fetal middle-cerebral-artery peak-systolicvelocity (MCA-PSV) for diagnosis of fetal anemia has reduced the number of invasive tests in the assessment of red cell alloimmunised pregnancies by $>70 \% .^{3}$ Measurement of fetal MCA-PSV has a predictable relationship with fetal hemoglobin. ${ }^{3-5}$ The decreasing red-cell-mass leads to decreased blood viscosity and increased cardiac output resulting in increased fetal arterial-PSV. MCA-PSV is mainly

\section{CORRESPONDENCE}

Dr Umesh Shrestha

Department of Radiodiagnosis and Imaging, Civil Service Hospital, Kathmandu, Nepal. Email: documesh22@hotmail.com

Phone: +977-9851134799 used for the prediction of fetal anemia ${ }^{5-7}$ however; a preliminary study ${ }^{8}$ has reported increased MCA-PSV in IUGR fetuses.

Detection of truly high-risk pregnancy needs a strong tool with suitable reference ranges, the accuracy of which is important. Several fetal MCA-PSV reference ranges are currently in use $^{3}$ however none are available for Nepalese population. This study was conducted to establish the reference values for fetal MCA-PSV in uncomplicated pregnancies between 19-40 weeks gestation in Nepalese population.

The papers in this journal are published under the terms of the Creative Commons Attribution License. Users are allowed to read, download, copy, distribute, print, search, or link to the full texts of the articles in this journal without asking prior permission from the publisher or the author. 


\section{METHODS}

This was a prospective cross-sectional study done in the Department of Radiology and Imaging, Tribhuvan University Teaching Hospital, Nepal from September 2009 to August 2010. Four hundred singleton pregnancies between 19-40 weeks of gestation without any known risk factors of adverse pregnancy outcome who were referred for routine obstetric ultrasonography were studied. Those with undetermined period of gestation, maternal smoking, multiple pregnancy, diagnosed fetal abnormality in current pregnancy, previous history of preeclampsia, intrauterine growth retardation, abruptio placenta or preterm delivery, history of any pre-existing medical condition (such as hypertension, diabetes mellitus, renal disease), risk of developing fetal anemia including Rhesus negative women and those not willing to give consent for the study were excluded. Gestational age was determined from ultrasound examination before 20 weeks of gestation or from last menstrual period. While calculating the gestational age, those at three days and below were taken in lower gestational week and those after four days and above were taken in higher gestational week.

The doppler examination of fetal middle cerebral artery was done within $2 \mathrm{~mm}$ after its origin from the internal carotid artery with the angle of insonation kept at $<20$ degrees in all cases. The data obtained were compiled and analyzed using standard statistical analysis. SPSS 16.0 and Microsoft Excel were utilized for the data analysis and presentation. Pearson correlation was used to see the relation of doppler parameters with gestational age. Linear regression equations were calculated and percentile fitted values were obtained for the parameters at different gestational age. Normograms and percentile fitted curves were obtained.

\section{RESULTS}

During the period of this study 400 singleton uncomplicated pregnancies between 19-40 weeks of gestations were enrolled. The maternal age ranged from 18 to 36 years with the mean age being 24.94 \pm 3.49 years. Majority of the patients $(10 \%)$ were at 19 weeks of gestation and the least number of pregnancies $(2.5 \%)$ were at 31 weeks.

Table 1. Mean and standard deviation of middle cerebral artery peak systolic velocity at different gestational age $(n=400)$.

\begin{tabular}{|c|c|c|}
\hline $\begin{array}{l}\text { Gestational Age } \\
\text { (weeks) }\end{array}$ & Mean MCA-PSV & $\begin{array}{l}\text { Standard } \\
\text { Deviation }\end{array}$ \\
\hline 19 & 22.2888 & 3.14365 \\
\hline 20 & 23.4823 & 3.62789 \\
\hline 21 & 23.6881 & 3.66769 \\
\hline 22 & 24.4428 & 3.74018 \\
\hline
\end{tabular}

$\begin{array}{ll}25.0800 & 4.69530 \\ 27.6214 & 2.98443 \\ 28.4177 & 3.97432 \\ 33.4629 & 4.06673 \\ 36.1331 & 3.09927 \\ 38.8000 & 6.07492 \\ 42.8677 & 5.64531 \\ 46.9617 & 8.39603 \\ 48.2060 & 6.73701 \\ 52.3294 & 10.56475 \\ 53.3341 & 10.12149 \\ 55.8285 & 11.25555 \\ 59.1872 & 8.11738 \\ 61.0894 & 9.75593 \\ 62.2396 & 9.94632 \\ 64.2150 & 9.10504 \\ 64.5700 & 9.65823 \\ 67.8408 & 9.67187\end{array}$

Table 2. Percentile values (5th, 50th and 95th) of middle cerebral artery peak systolic velocity at different gestational age $(n=400)$.

\begin{tabular}{llll}
\hline $\begin{array}{l}\text { Gestational } \\
\text { Age }\end{array}$ & Percentile & & \\
\hline & 5th & 50th & 95th \\
19 & 17.5380 & 21.8750 & 28.1860 \\
20 & 18.0800 & 23.6150 & 29.3865 \\
21 & 18.2000 & 24.1350 & 30.8600 \\
22 & 19.1200 & 24.1900 & 33.1000 \\
23 & 19.4100 & 25.4400 & 36.0100 \\
24 & 23.4700 & 27.5300 & 36.6320 \\
25 & 24.0400 & 28.6300 & 39.0800 \\
26 & 27.5500 & 32.5700 & 40.3600 \\
27 & 29.9400 & 36.4100 & 42.4700 \\
28 & 31.4900 & 38.9700 & 50.8400 \\
29 & 34.5200 & 42.8900 & 51.2200 \\
30 & 35.9700 & 46.5150 & 56.4800 \\
31 & 37.4300 & 48.7850 & 59.5800 \\
32 & 38.7500 & 50.4250 & 67.6800 \\
33 & 39.1500 & 51.6400 & 71.9300 \\
34 & 40.4325 & 54.3950 & 76.7345 \\
35 & 42.2330 & 58.1400 & 77.1370 \\
36 & 42.9600 & 59.6650 & 80.0200 \\
37 & 44.4550 & 63.5100 & 81.2525 \\
38 & 45.7565 & 65.0450 & 84.2550 \\
39 & 47.1160 & 66.7400 & 84.2690 \\
40 & 47.6400 & 69.9600 & 84.4000 \\
\hline & & & \\
34 & & & \\
36 & & &
\end{tabular}


The fetal peak systolic blood flow in the middle cerebral artery showed significant correlation with period of gestation with a Pearson correlation (r) of 0.912 (p value: 0.0001 ). Mean MCA-PSV was 22.35 \pm 3.05 at 19 weeks of gestation, which increased to $67.73 \pm 9.92$ at 40 weeks (Table 1). Table 2 shows the reference values of MCA-PSV with $5^{\text {th }}, 50^{\text {th }}$ and $95^{\text {th }}$ percentile values. Linear regression was obtained for each Doppler parameter, which shows highly significant correlation ( $\mathrm{p}$ value $=0.0001$ ) between MCA-PSV and gestational age.

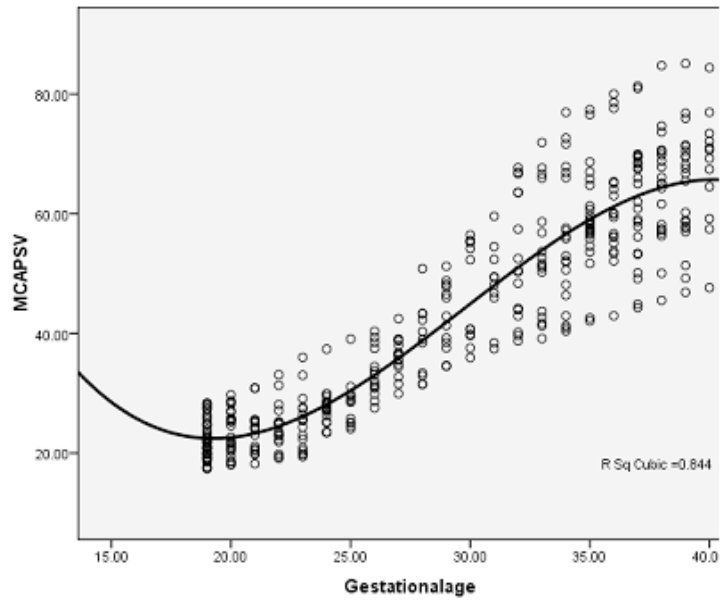

Figure 1. Scattered diagram showing linear correlation of MCA-PSV against period of gestation.

The scattered diagram (Figure 1) showing linear correlation of MCA-PSV against period of gestation shows continuous increment of MCA-PSV with increasing gestational age. The increment of MCAPSV between 19-40 weeks is more pronounced in the mid of second half of pregnancy and is less during early and later part of second half of pregnancy.
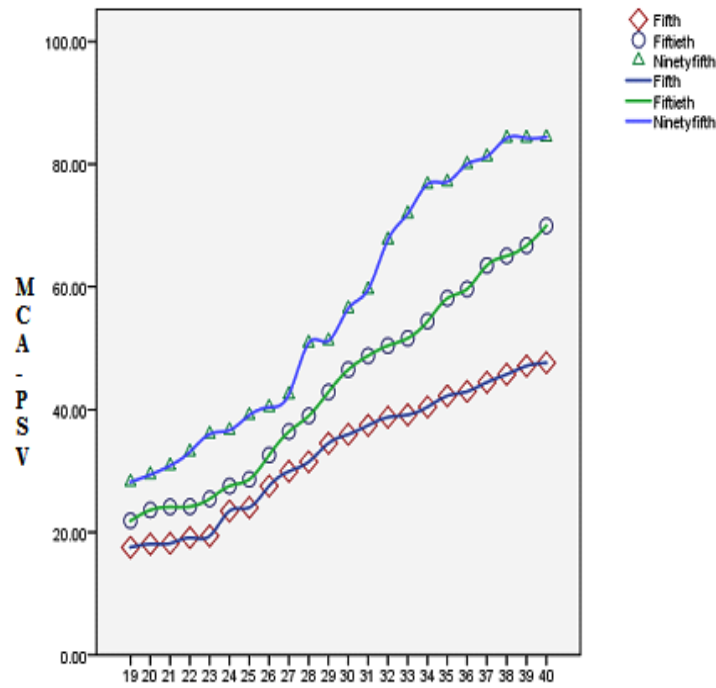

Figure 2. Scattered diagram of MCA-PSV against period of gestation with 5 th, 50 th and 95 th percentile lines.
Gestational age specific normograms with $5^{\text {th }}, 50^{\text {th }}$ and $95^{\text {th }}$ percentile fitted lines were constructed (Figure 2). The lines show continuous increment of the MCA-PSV with increasing period of gestation.

\section{DISCUSSION}

Cross-sectional observations were obtained in 400 uncomplicated singleton pregnancies between 19 and 40 weeks of gestation. Reference ranges for fetal MCA-PSV was constructed based on these observations. The MCA-PSV showed significant increase with increasing period of gestation with a significant positive correlation with period of gestation $(\mathrm{r}=0.912, \mathrm{p}<0.0001)$. Although this confirms other studies $^{2,9-13}$ the reference values for MCA-PSV in this study varied from other studies, which are as follows.

Kurmanavicius $\mathrm{J}$ et $\mathrm{al}^{12}$ in a cross sectional study involving 331 normal pregnancies between 19-40 weeks also showed that MCA-PSV increases with increasing period of gestation and the $5^{\text {th }}$ percentile of both the studies were similar however the $50^{\text {th }}$ and $95^{\text {th }}$ of our study were higher than the study conducted by Kurmanavicius $\mathrm{J}$ et al. Ebbing et $\mathrm{al}^{10}$ in a study with 161 singleton pregnancies between 19-40 weeks period of gestation also showed that the MCA-PSV increases with increasing gestational age but the reference values were lower than this study. Tongsong et $\mathrm{al}^{11}$ in a prospective cross-sectional descriptive study in which low-risk singleton pregnancies with accurate gestational age were recruited into the study showed a continuous increase in MCA-PSV over the period from 11-22 weeks. The $5^{\text {th }}$ and $50^{\text {th }}$ percentile of MCA-PSV in 19-22 weeks were lower than our study, however the $95^{\text {th }}$ percentile were higher than our study.

Tan et $\mathrm{al}^{2}$ in a study conducted in 329 normal Asian pregnant women between 16-40 weeks of gestation comparing the reference values for MCA-PSV between Asian and non-Asian obstetric populations also showed that the MCA-PSV in Asian women increases with increasing period of gestation. The reference range in that study was lower than our study. This seems to suggest that there may be essential differences not only between Asian and non-Asian populations but also among various Asian countries, regions and ethnic groups. Thus this emphasizes the need to obtain the reference value for Nepalese population and also various ethnic groups among the Nepalese populations as using a non-local reference range could pick up more false-positives for anemia, especially in the later gestational ages. However, we note that these postulations have not been validated by a correlation of fetal and neonatal hemoglobin levels in our own population. It is thus hoped that this study will encourage more work to be done to ascertain and validate this local reference range for MCA-PSV, and for it to be utilized in the local setting in future for obstetric practice. 


\section{CONCLUSIONS}

Reference ranges for peak systolic velocity of fetal middle cerebral artery were constructed for Nepalese population. Continuous increment in the peak systolic volume with advancing gestational age was obtained. The percentile fitted values and normograms were also obtained which will be valuable for the serial measurement of the peak systolic volume of the middle cerebral artery for complicated pregnancies.

\section{REFERENCES}

1. FitzGerald DE, Drumm JE. Non-invasive measurement of human fetal circulation using ultrasound: a new method. Br Med J. 1977;2(6100):1450- 1

2. Tan KB, Fook-Chong SM, Lee SL, Tan LK. Foetal peak systolic velocity in the middle cerebral artery: an Asian reference range. Singapore Med J. 2009;50(6):584-6.

3. Mari G, Deter RL, Carpenter RL, Rahman F, Zimmerman $\mathrm{R}$, Moise KJ Jr, et al. Noninvasive diagnosis by Doppler ultrasonography of fetal anemia due to maternal redcell alloimmunization. Collaborative group for Doppler assessment of the blood velocity in anemic fetuses. $\mathrm{N}$ Engl J Med. 2000;342(1):9-14.

4. Bartha JL, Illanes S, Abdel-Fattah S, Hunter A, Denbow M, Soothill PW. Comparison of different reference values of fetal blood flow velocity in the middle cerebral artery for predicting fetal anemia. Ultrasound Obstet Gynecol. 2005;25(4):335-40.

5. Mari G, Adrignolo A, Abuhamad AZ, Pirhonen J, Jones DC, Ludomirsky A, et al. Diagnosis of fetal anemia with Doppler ultrasound in the pregnancy complicated by maternal blood group immunization. Ultrasound Obstet Gynecol. 1995;5(6):400-5.
6. Zimmermann R, Durig P, Carpenter RJ, Mari G. Longitudinal measurement of peak systolic velocity in the fetal middle cerebral artery for monitoring pregnancies complicated by red cell alloimmunisation: a prospective multicentre trial with intention-to-treat. BJOG. 2002;109(7):746-52.

7. Oepkes D, Seaward PG, Vandenbussche FP, Windrim R, Kingdom J, Beyene J, et al. Doppler ultrasonography versus amniocentesis to predict fetal anemia. N Engl J Med. 2006;355(2):156-64.

8. Ozcan T, Sbracia M, d'Ancona RL, Copel JA, Mari G. Arterial and venous Doppler velocimetry in the severely growth restricted fetus and associations with adverse perinatal outcome. Ultrasound Obstet Gynecol. 1998;12(1):39-44.

9. Mari G, Abuhamad AZ, Cosmi E, Segata M, Altaye M, Akiyama M. Middle cerebral artery peak systolic velocity: technique and variability. J Ultrasound Med. 2005;24(4):425-30

10. Ebbing C, Rasmussen S, Kiserud T. Middle cerebral artery blood flow velocities and pulsatility index and the cerebroplacental pulsatility ratio: longitudinal reference ranges and terms for serial measurements. Ultrasound Obstet Gynecol. 2007;30(3):287-96.

11. Tongsong T, Wanapirak C, Sirichotiyakul S, Tongprasert F, Srisupundit K. Middle cerebral artery peak systolic velocity of healthy fetuses in the first half of pregnancy. $\mathrm{J}$ Ultrasound Med. 2007;26(8):1013-7.

12. Kurmanavicius J, Streicher A, Wright EM, Wisser J, Muller R, Royston P. Reference values of fetal peak systolic blood flow velocity in the middle cerebral artery at 19-40 weeks of gestation. Ultrasound Obstet Gynecol. 2001;17(1):50-3.

13. Scheier M, Hernandez-Andrade E, Carmo A, Dezerega $\mathrm{V}$, Nicolaides KH. Prediction of fetal anemia in rhesus disease by measurement of fetal middle cerebral artery peak systolic velocity. Ultrasound Obstet Gynecol. 2004;23(5):432-6. 